ERDC/CRREL TR-03-14

August 2003

\title{
On-Site Processing and Subsampling of Surface Soil Samples for the Analysis of Explosives
}

\author{
Alan D. Hewitt and Marianne E. Walsh \\ U.S. Army Engineer Research and Development Center \\ Cold Regions Research and Engineering Laboratory \\ 72 Lyme Road, Hanover, New Hampshire 03755-1290
}

Final report
Approved for public release; distribution is unlimited.
$\begin{array}{ll}\text { Prepared for } & \begin{array}{l}\text { U.S. Army Environmental Center } \\ \text { Aberdeen Proving Ground, Maryland 21010-5401 }\end{array} \\ \text { Monitored by } & \begin{array}{l}\text { U.S. Army Environmental Center } \\ \text { Aberdeen Proving Ground, Maryland 21010-5401 }\end{array}\end{array}$

ABSTRACT

The on-site implementation of a sampling and analysis plan for the determination of explosives residues exposed a large uncertainty in our ability to quickly obtain representative subsamples from either large ( $>500 \mathrm{~g})$ composite and/or large discrete samples. To improve the representativeness of on-site analysis, a simple on-site processing (grinding and mixing) and subsampling protocol was evaluated. Surface samples from three firing range characterization activities were taken through a procedure where the bulk samples were air-dried, sieved (\#10, $2 \mathrm{~mm}$ ), ground with a portable hand-operated mill, mixed, and then subsampled using layered bedding technique. This approach reduces laboratorysubsampling variance for both sparsely vegetated and vegetated surface soils. Moreover, during a subsequent dynamic sampling and analysis effort, this protocol was successful in ranking explosives residue concentrations associated with a specific military training activity. 


\section{SUBJECT TERMS}

Explosives

Sample processing

Soil

Subsampling

Sponsor's Report No.: SFIM-AEC-PC-CR-2003013 


\section{CONTENTS}

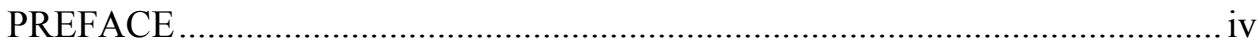

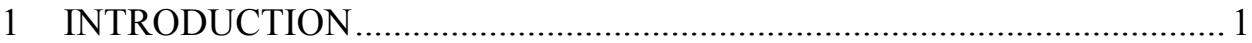

2 EXPERIMENTAL MATERIALS AND METHODS ................................... 4

Field studies at Camp Ethan Allen, Vermont .................................................. 5

Field studies at Fort Bliss, New Mexico ..................................................... 7

Field studies at Fort Greely, Alaska .......................................................... 8

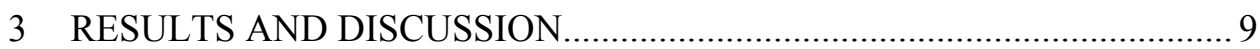

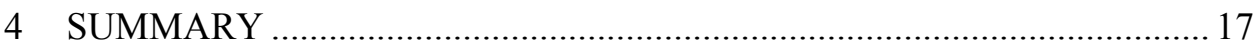

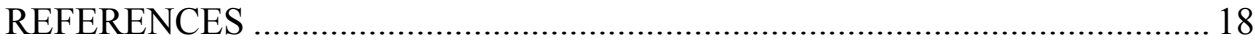

\section{TABLES}

Table 1. Surface soil TNT concentrations established where two 155-mm howitzer rounds had been blown in place.

Table 2. Surface soil TNT concentrations for seven replicate subsamples taken from duplicate field samples collected with coring tool at a distance of $10 \mathrm{~m}$ from the location where the \#1 howitzer round was blown in place

Table 3. Explosives residue concentrations in surface soil samples collected

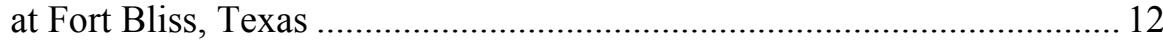

Table 4. Explosives residue concentrations in surface soil samples collected, processed, and analyzed at Fort Greely, Alaska, and further processed and analyzed at CRREL 


\section{PREFACE}

This report was prepared by Alan D. Hewitt, Research Physical Scientist, and Marianne E. Walsh, Chemical Engineer, Environmental Sciences Branch, U.S. Army Engineer Research and Development Center, Cold Regions Research and Engineering Laboratory, Hanover, New Hampshire.

Funding for this work was provided by the U.S. Army Environmental Center, Martin H. Stutz, Project Monitor. Technical reviews were provided by Dr.

Clarence L. Grant and Charles Ramsey.

This publication reflects the personal views of the authors and does not suggest or reflect the policy, practices, programs, or doctrine of the U.S. Army or Government of the United States. The contents of this report are not to be used for advertising or promotional purposes. Citation of brand names does not constitute an official endorsement or approval of the use of such commercial products.

The Commander and Executive Director of the Engineer Research and Development Center is Colonel James R. Rowan, EN. The Director is Dr. James R. Houston. 


\title{
On-Site Processing and Subsampling of Surface Soil Samples for the Analysis of Explosives
}

\author{
ALAN D. HEWITT AND MARIANNE E. WALSH
}

\section{INTRODUCTION}

There are several challenges confronting efforts to characterize military training and testing ranges for chemical residues associated with the detonation of high explosives and propellants. Overall, accessibility to active firing ranges is, and will remain, one of the greatest challenges as a result of training schedules and the liability associated with unexploded ordnance (UXOs). Other challenges include their size (ranges cover tens to thousands of square kilometers), location (often remote), terrain, and vegetation. Small trees and brush encumber mobility and visibility, and ground cover-e.g., grasses, mosses, and other types of vegetation-hinders traditional collection techniques and contributes to the organic matter in the samples collected for the analysis of explosives residues.

Using a sampling strategy that focuses on the collection of the immediate ground surface interface, i.e., vegetation and/or the first couple centimeters of top soil, is imperative because of the major dispersion pathway for energetic residues associated with projectile firing and the detonation of munitions. Both of these events form airborne clouds composed of various sized and shaped particles, the majority of which are locally (within $100 \mathrm{~m}$ ) deposited on the ground surface. The major products of the detonation of energetic materials are typically $\mathrm{CO}_{2}$, $\mathrm{CO}, \mathrm{H}_{2} \mathrm{O}, \mathrm{N}_{2}$, and carbon (i.e., "soot" [U.S. Army Materiel Command 1972]). However, post-blast residue studies using snow as a collection surface have established the presence of trace quantities of explosives (Jenkins et al. 2000a, 2000b), while site characterization activities have reported the sporadic presence of large quantities of explosives around partially detonated munitions (Jenkins et al. 2001).

Low-order or partial detonations result in the distribution of particles of the high-explosive filler that range from submicron to several centimeters or larger in 
diameter. High-order detonations also distribute particles of unconsumed filler. It is anticipated that the explosives residues liberated during a live-fire exercise involving properly functioning munitions (i.e., high-order detonations) fall within the submicron to micron particle-size category. However, the high-order detonation of a $155-\mathrm{mm}$ howitzer round blown in place with a demolition block of C4 was observed to distribute TNT particles that ranged in size from submicron to a couple millimeters in diameter (Taylor et al. in prep). The firing of mortar and howitzer projectiles involves the detonation of a propellant that is composed of nitrocellulose (NC) and often some other explosives. At a 105-mm howitzer firing position, explosives residues were observed to be associated with elongated particles (aspect ratio of greater than 20 to 1) that were often a couple millimeters in length. ${ }^{*}$ Presumably these particles were NC fibers that in the case of the propellant used to fire the $105-\mathrm{mm}$ howitzer rounds contain about $11.5 \%$ 2,4-DNT $\mathrm{w} / \mathrm{w}$ as a plasticizer.

All of these particles of explosives residues remain as solids at environmental temperatures. However, they are subject to degradation by dissolution, phototransformation, and biological processes to various degrees. The combination of this dispersion pathway, their physical size and shape, and the variables associated with degradation make their distribution on the surface very heterogeneous. To address both analyte heterogeneity and spatial heterogeneity, the collection of large composite samples has been recommended when the objective is to acquire average surface residue concentrations (Jenkins et al. 1996, 1997a, 1997b).

Both multi-increment composite samples and large discrete samples require extensive grinding and mixing before they can be representatively subsampled. Sample mixing procedures that have traditionally been used in the field prior to splitting field samples usually yield subsamples with a large amount of variance. Grant et al. (1996) showed in a statistical analysis of archived data for the analysis of split soil samples, used as part of an intra-laboratory quality control/quality assurance program, that an acceptance window of a factor of four (relative percent difference "RPD" $120 \%$ ) was necessary for explosives. Moreover, this paper recommended that improvements should be made to reduce the range of acceptance. In our initial attempt to use a sampling and analysis plan on a military firing range we used a multi-increment approach to build subsamples. Fifteen or more increments were taken from large discrete or composite samples once they were returned from the field for on-site extraction and analysis. This method of subsampling was found to be subject to a very large degree of variability, i.e., analyte concentrations ranged over two orders of magnitude from the same sample (Hewitt 2002). The objective of this study was to reduce subsampling

\footnotetext{
*Personal communication, Susan Taylor, Research Physical Scientist, CRREL, 2002.
} 
variance for explosives residues in surface samples collected and analyzed on site during characterization activities associated with military training ranges. Lastly, the grinding, mixing, and subsampling protocol developed for on-site use should not be cumbersome or time-consuming or excessively expensive. 


\section{EXPERIMENTAL MATERIALS AND METHODS}

A combination of particle-size reduction and an increase in the size of the subsample extracted for analysis is often used to reduce variance among subsample determinations (ASTM 1998). To mechanically reduce the particle size of a sample, it is often necessary to have a low water content in the material being ground. Mechanical grinding or sieving turns a moist soil into a paste that cannot easily be removed from equipment surfaces.

To minimize the drying period, samples were spread on a large clean surface. We accomplished this task by cutting the sides of the $30-\times 38-\mathrm{cm}$ sample collection bag and evenly spreading the sample over a $24-\times 70-\mathrm{cm}$ area. Depending on the sample size, moisture, soil texture (clay, silt, sand), vegetation content, and the ambient temperature and relative humidity, this step typically took between 12 and 24 hours; however, some samples required a longer period. Air-dried samples were passed through a \#10 sieve $(2 \mathrm{~mm})$ to remove large particles (pebbles and large pieces of vegetation, e.g., sticks). To assist this operation a wooden stand was made to hold the 20-cm-O.D. sieve over a 23-cm-O.D. disposable aluminum pan (pie plate). Grass, moss, and roots that failed to pass through the sieve were combined with the $<2$-mm portion of the sample. This vegetation portion frequently contains a significant amount of propellant residues (Walsh et al. in prep). Typically, samples were sieved in 15 minutes or less. The $<2$-mm portion and the vegetation were ground with a portable hand mill (Thomas Scientific). This step takes anywhere from 5 to 45 minutes depending on the sample size, texture, and moisture content.

For highly vegetated samples it was determined that, on average, $8 \%$ of the mass of the ground sample was greater than $0.6 \mathrm{~mm}$ (\#30 sieve), 32\% was between $0.6 \mathrm{~mm}$ and $0.25 \mathrm{~mm}$ (between \#30 and \#60 sieve), and $60 \%$ was less than $0.25 \mathrm{~mm}$ in size. The portion retained by the \#30 sieve was composed mostly of vegetation (grass and/or root fibers) that had a large length-to-width aspect ratio. For sparsely vegetated surface samples the percentage of smallest fraction was about the same (60\%); however, the two larger fractions varied depending on the sand content.

Once ground, a sample was placed in a plastic bag and thoroughly shaken to mix the contents. The contents of the bag then were slowly poured onto a fresh sheet of aluminum foil, in a long rectangular pattern $(1 \times 20$ width to length), maintaining a uniform shape (width and length) while making at least twenty passes to form a layered cake. Subsamples were removed by taking a cross section of the pile that was $1 \mathrm{~cm}$ or greater in width using two large spackling knives to isolate and transfer them to disposable cups for weighing. This sub- 
sampling protocol took no more than five minutes to perform. For the majority of samples that were collected for this study, the subsample taken for extraction and analysis weighed between 20 and $70 \mathrm{~g}$.

The sieve, hand mill, and spackling knives were the only pieces of equipment that were reused. Between samples these items were decontaminated by rinsing with tap water, wiping with a clean paper towel, and spraying (small spray bottle) with hardware store acetone while holding over a bucket. The hand mill was composed of four parts held together with wing nuts and was easy to disassemble and assemble, and two sieves were alternately used, because they required a longer drying period.

In the field the subsample was extracted by transferring to a wide-mouth glass bottle and adding approximately twice the volume ( $2 \mathrm{~mL}$ per $\mathrm{g}$ of sample) of hardware store acetone. After shaking the contents of the bottle a couple times during a 20-minute extraction period, the particles were allowed to settle. In the laboratory subsample, extraction and analysis followed the guidelines in Method 8330 (U.S. EPA 1994), i.e., subsamples were extracted with acetonitrile in a water-cooled sonic bath for 18 hours. In both cases, once a clear solvent layer formed, a 3-mL aliquot was drawn into a disposable syringe and filtered by passing through a $25-\mathrm{mm}$ Millex SR $(0.5-\mu \mathrm{m})$ filter that was attached via a Luer-Lok fitting. The filtered extract was directly transferred to a 2-mL amber deactivated glass vial. For high-performance liquid chromatography analysis the solvent extract was diluted 1:3 with water for analysis.

\section{Field studies at Camp Ethan Allen, Vermont}

On February 28, 2002, eight 155-mm howitzer rounds filled with TNT (6.8 $\mathrm{kg}$ ) were blown in place in a large snow-covered field by EOD personnel from the Vermont Air National Guard. The location of the field was on the back side of a practice range where only inert rounds were fired (i.e., outside of an active impact area). This exercise was performed as part of a program focused on the characterization of explosives residues deposition from the detonation of Army munitions (Hewitt et al. in prep). Each round was hung about $1.3 \mathrm{~m}$ above the snow surface by hooking to a metal chain that attached to a four-legged wood frame (tall sawhorse). A $0.57-\mathrm{kg}$ block of $\mathrm{C} 4$ and a radio-signal-initiated blasting cap were taped to the side of each round. Following detonation, several surface snow samples were collected within the area covered with soot for seven of the rounds. These surface samples were used to estimate the concentrations of high explosives that were deposited from the blowing in place of $155-\mathrm{mm}$ howitzer rounds (Hewitt et al. in prep). The soot plumes from Rounds \#4 and \#1 showed the lowest and highest deposition of TNT. The corresponding mean snow surface 
TNT concentrations established for these two rounds were $1.5 \mu \mathrm{g} / \mathrm{m}^{2}$ and $2.2 \times$ $10^{5} \mu \mathrm{g} / \mathrm{m}^{2}$. Based on mean deposition values it was estimated that $99.9992 \%$ of the TNT was consumed during the detonation of Round \#4 and only $98 \%$ was consumed for Round \#1. By assuming that these energetic residues become evenly distributed over the ground under the area of the plume once the snow melts, and that they would be retained in the top $0.5 \mathrm{~cm}$ of soil (density 1.7 $\mathrm{g} / \mathrm{cm}^{3}$ ), the corresponding overall average surface soil concentrations for Rounds \#4 and \#1 would respectively be 0.002 and $26 \mathrm{mg} / \mathrm{kg}$ for TNT.

Surface soil (ground surface) samples were initially collected at these sites on April 30, 2002, after the snow had melted, with repeat collections on July 31st and October 10th of the same year. The location of the two detonation points was initially recorded and then re-established using a global positioning system (GPS). Approximately two weeks prior to the first sampling event, as part of the Camp Ethan Allen range management program, the surface vegetation was burned in the field where the $155-\mathrm{mm}$ rounds had been detonated. During the April sampling event approximately $30 \%$ of the surface was covered with patches of burnt vegetation. In general, these locations were covered with grasses and mosses, and the topsoil consisted of sandy soils, pebbles, and rocks. Composite surface samples were collected in concentric rings of 1-, 3-, 5-, and 10-m radius around the detonation point with both a small coring tool (2.1-cm I.D.) and metal scoop. With the coring tool the number of increments proportionally increased relative to the size of the circle. Respectively, 10, 30, 50, and 100 increments (plugs) spaced approximately $62 \mathrm{~cm}$ from each other were collected for the 1-, 3-, 5-, and 10-m-radius rings (moist composite sample weights ranged from 100 to $850 \mathrm{~g}$ ). A 30-increment composite sample was built with the metal scoop (moist sample weights averaged $1 \mathrm{~kg}$ ) independent of size of the ring. The surface area obtained with the scoop was approximately $20 \mathrm{~cm}^{2}$. All of the composite samples contained vegetation and soil from the top 1 to $2 \mathrm{~cm}$ of the ground surface.

In April one composite sample was collected where Round \#4 had been detonated and 12 composite samples were collected at the Round \#1 location. For Round \#4 the coring tool was used and a single composite sample was taken at a distance of $3 \mathrm{~m}$. For Round \#1, duplicate composite samples were collected at distances of $1,3,5$, and $10 \mathrm{~m}$ with the coring tool; a single composite sample also was collected at each of these distances with the metal scoop. For the subsequent sampling events composite samples were collected only around Round \#1. In both July and October duplicate composite samples were collected at distances of 1, 3, 5, and $10 \mathrm{~m}$ with the coring tool. Also, a single 30 -increment composite sample was collected at each distance with the metal scoop in October. All samples were stored in plastic bags and held at $4{ }^{\circ} \mathrm{C}$ until being processed at CRREL. 
Field studies at Fort Bliss, New Mexico

During a characterization study of the Dona Ana range at Fort Bliss, New Mexico, discrete and composite soil samples were collected to evaluate the processing and subsampling protocol in the field. Two locations were judgmentally selected for the collection of samples for on-site processing. Both sampling locations were within an artillery impact range that was covered with well-drained soils consisting of fine sands mixed with gravel. At one location a 30 -increment composite sample was collected within a 10- $\times 10$-m grid using a metal scoop. The sampling grid was positioned in an area where numerous pieces of high-explosive material were found on the surface. The pieces of high explosives presumably came from the partial (breached casing containing and surrounded by pieces of high explosives) detonation of two 90-mm recoilless rifle rounds that were found in the immediate area. The sampling activity was performed after all of the visible pieces ( 34 pieces, $67 \mathrm{~g}$ ) of high explosives were removed from the sampling grid.

At a second location within a ravine where a $155-\mathrm{mm}$ howitzer had partially detonated, a combination of discrete and composite samples was collected moving downgrade from this potential surface runoff source of high explosives. Discrete samples (approximately $100 \mathrm{~g}$ ) were collected with a metal spoon at distances of 1, 2, 3, 4, and $5 \mathrm{~m}$, and 30-increment composites samples (approximately $1 \mathrm{~kg}$ ) from a $2-\times 2-\mathrm{m}$ area within the intermittent runoff channel were collected at distances of 12 and $30 \mathrm{~m}$ with a metal scoop. At both the grid and ravine locations the samples were dry and free of vegetation. All these samples were stored in plastic bags.

All of these samples were processed (ground, mixed, and subsampled) on site. As a precaution, pebbles that did not pass through the \#10 sieve were carefully inspected. Particles suspected to be energetic materials (brittle to probing and having a light-orange-colored surface) were evaluated using an Expray kit (Thiboutot et al. 2002). No particles were positively identified as being high explosives. For the composite sample collected in the 10- $\times 10-\mathrm{m}$ grid, seven replicate subsamples were taken, while only duplicate subsamples were taken from the ravine samples. In addition to the samples taken from the artillery range, two composite samples that had been collected at howitzer firing positions were also processed. These two additional samples served as field equipment blanks (i.e., to assess cross contamination between the on-site processing of samples). The surface soils from the firing positions were well drained and consisted of fine sands and silts. The subsamples that were obtained in the field were wrapped in aluminum foil, placed in a small plastic bag, then returned to the large sample bag. All of the samples were returned to CRREL for extraction and analysis. 


\section{Field studies at Fort Greely, Alaska}

One of the ongoing range characterization objectives at the Donnelly Training Area, Alaska, is to assess the fate and transport of explosives residues (Walsh et al. in prep). In 2001 the majority of samples collected in front of M119A 105-mm howitzer gun positions at five different training locations showed the presence of 2,4-DNT. Prior to the 2002 field sampling events, it was decided that more extensive sampling should be performed around a howitzer firing position in both a vegetated and a sparsely vegetated training location. Furthermore, the selection of appropriate (highest concentrations of 2,4-DNT) sampling locations would be established using on-site analysis. The selection of sampling locations was based on surface concentration estimates for composite samples built by combining 30 increments collected within a $2-\times 6-\mathrm{m}$ grid, $25 \mathrm{~m}$ directly in front of each gun position. Sample collection, on-site sample processing, subsampling, and analysis took place over a five-day period immediately following a 105-mm howitzer-training exercise. Prior to performing this task it was decided that duplicate subsamples would be taken for on-site analysis from each composite sample.

The sampling team used a coring tool with a $6.1-\mathrm{cm}$ I.D. to obtain the $30-$ increment composite samples in the grids at the vegetated training locations and a metal scoop in the grids that were sparsely vegetated. In general the composite samples ranged between 1.5 and $2.5 \mathrm{~kg}$ in moist weight, and those obtained with the coring tool tended to weigh the most. As a result most of the vegetated composite samples took more than two days to dry prior to proceeding with sample processing and subsampling protocol described above. On-site analysis was performed with a field-portable gas chromatograph (GC) equipped with a thermionic ionization detector (TID). A thorough description and evaluation of this field-portable GC-TID system for the determination of explosives has been published elsewhere (Hewitt et al. 2001). For the determination of 2,4-DNT in the field, a $1-\mu \mathrm{L}$ aliquot of the subsample extract was injected directly onto the GC column and the analysis was completed within six minutes. 


\section{RESULTS AND DISCUSSION}

Table 1 shows the TNT concentrations determined in composite samples collected at Camp Ethan Allen. These composite samples were processed and subsampled following the technique described above and were analyzed by HPLC (U.S. EPA 1994). To evaluate this sample preparation procedure, duplicate subsamples were taken from every sample except two that had seven replicate subsamples removed for analysis. Overall, TNT concentrations in the samples collected where both Rounds \#1 and \#4 had been blown in place agreed with the anticipated surface concentrations that were based on the estimates for snow surface residue plumes. Mean TNT concentrations for these two locations found during the April sampling events were, respectively, 49 and $<0.05 \mathrm{mg} / \mathrm{kg}$ for Rounds \#1 and \#4. With respect to the sample processing and sub-sampling technique, the mean relative percent difference (RPD) was $48 \%$ for the duplicate subsamples with detectable analyte concentrations. Twice $(8 \%)$ the range between the duplicate subsample values was greater than a factor of four. However, in most (16 of 24) cases, the range was less than a factor of two.

Table 2 shows the results for two composite samples that had seven replicate subsamples removed for analysis. The relative standard deviation for these two data sets was 4.9 and $13.9 \%$, and the range in values for both sets was far less than a factor of two.

Other observations are that the burning of the surface vegetation did not eliminate TNT residues, and it appears that among the sampling tools and protocols used, the stainless steel scoop 30-increment approach produced more representative field replicate samples. The mean RPDs for the corer was $27.2 \%$ whereas it was $58.6 \%$ for the corer. Moreover, twice, no detectable levels of TNT were found for duplicate composite samples that were collected with the coring tool, where either the previous or subsequent sampling event with this same sampling tool established significant concentrations.

Taylor et al. (in prep) determined that the residues of TNT from the blowing in place of Round \#1 consisted of small particles ranging in size from submicron to a couple of millimeters in diameter. These particles of unconsumed TNT from the main charge of the 155-mm howitzer round were randomly disbursed; however, smaller particles of TNT are more susceptible to dissolution, and it is anticipated that larger particles would tend to be thrown farther from the detonation point. This may explain why there was a reduction in the TNT concentrations with length of exposure for all the composite samples collected for the 1-mradius circle. However, this theory would not account for the failure to obtain any 
particles of TNT in the duplicate core samples collected at $3 \mathrm{~m}$ during the July sampling event.

Table 1. Surface soil TNT concentrations established where two 155-mm howitzer rounds had been blown in place.

\begin{tabular}{|c|c|c|c|c|c|c|}
\hline \multirow[b]{2}{*}{ Date } & \multirow[b]{2}{*}{ Sample location } & \multirow[b]{2}{*}{ Concentric circle } & \multirow[b]{2}{*}{ Sampling tool } & \multicolumn{2}{|c|}{ mg TNT/kg } & \multirow[b]{2}{*}{$\mathbf{R P D}^{\mathbf{a}}$} \\
\hline & & & & $\operatorname{Rep} 1$ & Rep 2 & \\
\hline $4 / 30$ & $\# 4$ & $3 m-A$ & Corer & $<0.05$ & $<0.05$ & - \\
\hline$"$ & $\# 4$ & $3 m-B$ & Corer & $<0.05$ & $<0.05$ & - \\
\hline$"$ & $\# 1$ & $10 \mathrm{~m}-\mathrm{A}$ & Corer & 0.137 & 0.829 & $143 \%$ \\
\hline$"$ & $\# 1$ & $10 \mathrm{~m}-\mathrm{B}$ & Corer & 4.50 & 12.9 & $96.5 \%$ \\
\hline$"$ & $\# 1$ & $10 \mathrm{~m}$ & Scoop & 21.3 & 29 & $30.6 \%$ \\
\hline$"$ & $\# 1$ & $5 \mathrm{~m}-\mathrm{A}$ & Corer & 5.83 & 9.56 & $48.5 \%$ \\
\hline$"$ & $\# 1$ & $5 \mathrm{~m}-\mathrm{B}$ & Corer & 43.6 & 61.4 & $33.9 \%$ \\
\hline$"$ & $\# 1$ & $5 \mathrm{~m}$ & Scoop & 8.14 & 19.6 & $82.6 \%$ \\
\hline$"$ & $\# 1$ & $3 \mathrm{~m}-\mathrm{A}$ & Corer & 201 & 252 & $22.5 \%$ \\
\hline$"$ & $\# 1$ & $3 m-B$ & Corer & 25.6 & 14.1 & $57.9 \%$ \\
\hline$"$ & $\# 1$ & $3 \mathrm{~m}$ & Scoop & 47.2 & 34.2 & $31.9 \%$ \\
\hline$"$ & $\# 1$ & $1 m-A^{b}$ & Corer & 5.34 & 12.0 & $76.8 \%$ \\
\hline$"$ & $\# 1$ & $1 \mathrm{~m}$ & Scoop & 143 & 126 & $12.6 \%$ \\
\hline $7 / 31$ & $\# 1$ & $10 \mathrm{~m}-\mathrm{A}$ & Corer & $5.5^{\mathrm{b}}$ & & \\
\hline$"$ & $\# 1$ & $10 m-B$ & Corer & $20.7^{b}$ & & \\
\hline$"$ & $\# 1$ & $5 \mathrm{~m}-\mathrm{A}$ & Corer & 4.26 & 3.59 & $17.1 \%$ \\
\hline$"$ & $\# 1$ & $5 \mathrm{~m}-\mathrm{B}$ & Corer & 0.135 & 0.100 & $29.8 \%$ \\
\hline$"$ & $\# 1$ & $3 \mathrm{~m}-\mathrm{A}$ & Corer & $<0.05$ & $<0.05$ & - \\
\hline$"$ & $\# 1$ & $3 \mathrm{~m}-\mathrm{B}$ & Corer & $<0.05$ & $<0.05$ & - \\
\hline$"$ & $\# 1$ & $1 \mathrm{~m}-\mathrm{A}^{\mathrm{b}}$ & Corer & 0.225 & 0.223 & $0.89 \%$ \\
\hline $10 / 10$ & $\# 1$ & $10 \mathrm{~m}-\mathrm{A}$ & Corer & 9.67 & 4.65 & $70.1 \%$ \\
\hline$"$ & $\# 1$ & $10 \mathrm{~m}-\mathrm{B}$ & Corer & 6.87 & 4.82 & $34.2 \%$ \\
\hline$"$ & $\# 1$ & $10 \mathrm{~m}$ & Scoop & 5.55 & 4.97 & $11.0 \%$ \\
\hline$"$ & $\# 1$ & $5 \mathrm{~m}-\mathrm{A}$ & Corer & 31.5 & 36.3 & $14.2 \%$ \\
\hline$"$ & $\# 1$ & $5 \mathrm{~m}-\mathrm{B}$ & Corer & 14.4 & 12.9 & $11.0 \%$ \\
\hline$"$ & $\# 1$ & $5 \mathrm{~m}$ & Scoop & 320 & 378 & $16.6 \%$ \\
\hline$"$ & $\# 1$ & $3 \mathrm{~m}-\mathrm{A}$ & Corer & 0.431 & 1.27 & $98.6 \%$ \\
\hline$"$ & $\# 1$ & $3 \mathrm{~m}-\mathrm{B}$ & Corer & 4.77 & 0.200 & $183 \%$ \\
\hline$"$ & $\# 1$ & $3 \mathrm{~m}$ & Scoop & 30.9 & 23.6 & $26.8 \%$ \\
\hline$"$ & $\# 1$ & $1 \mathrm{~m}-\mathrm{A}$ & Corer & $<0.05$ & $<0.05$ & - \\
\hline \multirow[t]{2}{*}{ " } & $\# 1$ & $1 \mathrm{~m}-\mathrm{B}$ & Corer & $<0.05$ & $<0.05$ & - \\
\hline & $\# 1$ & $1 \mathrm{~m}$ & Scoop & 3.96 & 4.19 & $5.64 \%$ \\
\hline
\end{tabular}


Table 2. Surface soil TNT concentrations for seven replicate subsamples taken from duplicate field (A and $B$ ) samples collected with coring tool at a distance of $10 \mathrm{~m}$ from the location where the \#1 howitzer round was blown in place.

\begin{tabular}{|c|c|c|}
\hline & \multicolumn{2}{|c|}{$\mathbf{m g}$ TNT/kg } \\
\hline Replicate \# & A & B \\
\hline 1 & 5.82 & 19.6 \\
\hline 2 & 5.38 & 19.0 \\
\hline 3 & 5.95 & 18.5 \\
\hline 4 & 5.37 & 18.9 \\
\hline 5 & 5.69 & 21.5 \\
\hline 6 & 5.77 & 26.8 \\
\hline 7 & 5.22 & 20.8 \\
\hline Mean & 5.60 & 20.7 \\
\hline Standard Deviation & 0.275 & 2.89 \\
\hline Relative Standard Deviation & $4.9 \%$ & $13.9 \%$ \\
\hline
\end{tabular}

Table 3 shows the results obtained for the analysis of subsamples prepared at Fort Bliss, Texas. Of the five duplicate subsamples, only two sets showed detectable levels of explosives residues. The two pairs of values established for TNT and two of its transformation products, 2A-DNT and 4A-DNT, were within a factor of 2.3 of one another. Only the composite sample from the $10-\times 10-\mathrm{m}$ grid was determined to contain explosives residues. This composite sample had seven replicate subsamples removed for analysis. The percent relative standard deviations (\% RSD) were below $6.5 \%$ for explosives analytes TNB, TNT, $2 \mathrm{~A}$ DNT, and 4A-DNT; however, it was above $50 \%$ for tetryl. The tetryl concentrations in these subsamples were confirmed by GC-ECD analysis (U.S. EPA 1999). Potential explanations for the discrepancy in variance between these different analytes among the subsample replicates taken from the grid sample, are that tetryl degraded during the sample extraction process (Jenkins and Walsh 1993), or that tetryl came from a different source (i.e., the booster). Degradation is inconsistent with the quality assurance used with these samples that showed good recoveries of tetryl from a spiked sandy soil. The booster, however, could be less crystalline in composition than the main charge of the $90-\mathrm{mm}$ recoilless rifle round; therefore, it would be more difficult to homogenize. 
The two samples processed as equipment blanks were sieved, ground, and subsampled after samples B-20 and B-23. The first of these had no detectable explosives analytes whereas B-23 had about $1.0 \mathrm{mg}$ TNT/kg and lesser amounts of two of its breakdown products (Table 3 ). The absence of these explosives residues in the equipment blank (BC-7) that was processed following this sample indicates the cleaning procedure was adequate. The inability to detect TNT in the ravine surface samples after moving only $2 \mathrm{~m}$ from a partially detonated round suggests that either this method of sample collection is inappropriate to detect surface runoff, or that this transport mechanism is not important in this situation.

Table 4 contains the on-site results for 2,4-DNT in duplicate subsamples taken from the composite samples collected at Fort Greely, Alaska. These samples are listed in the order that they were prepared for analysis. The two blank samples in this table were composed of sand that was purchased at a local hardware store (60-lb bag). Each portion (approximately $500 \mathrm{~g}$ ) was passed through the sieve, ground, and subsampled (single subsample) using the same protocol as the samples. The low concentrations estimates for these two blank samples again indicate that the equipment cleaning protocol was adequate. With respect to the sample processing and subsampling technique, the mean relative percent difference (RPD) was $52 \%$ for the duplicate subsamples. In this case the range between all of the duplicate values was a factor of 4 or less and in the majority (12 of 18) of cases it was less than a factor of two.

The two samples labeled OP were from an open burn pit used to destroy unused propellant. The two samples from the OP locations were composed of sand; those from Mark, Audrey, and Big Lake were from sparsely vegetated training locations; and those from Sally contained a lot of vegetation. Only two samples from Sally were processed and analyzed on site during this field investigation because they took several days to dry. These two samples from firing point Sally were analyzed on the last day of the field investigation just prior to performing the extensive sampling of the vegetated gun position. These two gun positions were pre-selected because both were located between two other guns, and range records showed that the greatest number of 105-mm howitzer rounds had been fired from this location during the recently completed training exercise.

The on-site sample processing, subsampling, and analysis allowed the analyst to identify gun positions at the two different types of training locations (vegetated and sparsely vegetated) for extensive sampling. Subsequent off-site analysis of composite samples from in front of the different guns at the various training locations confirmed that Mark Gun \#2 and Sally Gun \#5 had high levels of 2,4DNT and that further grinding on a ring mill did not improve the precision obtained in the field (Table 4). 


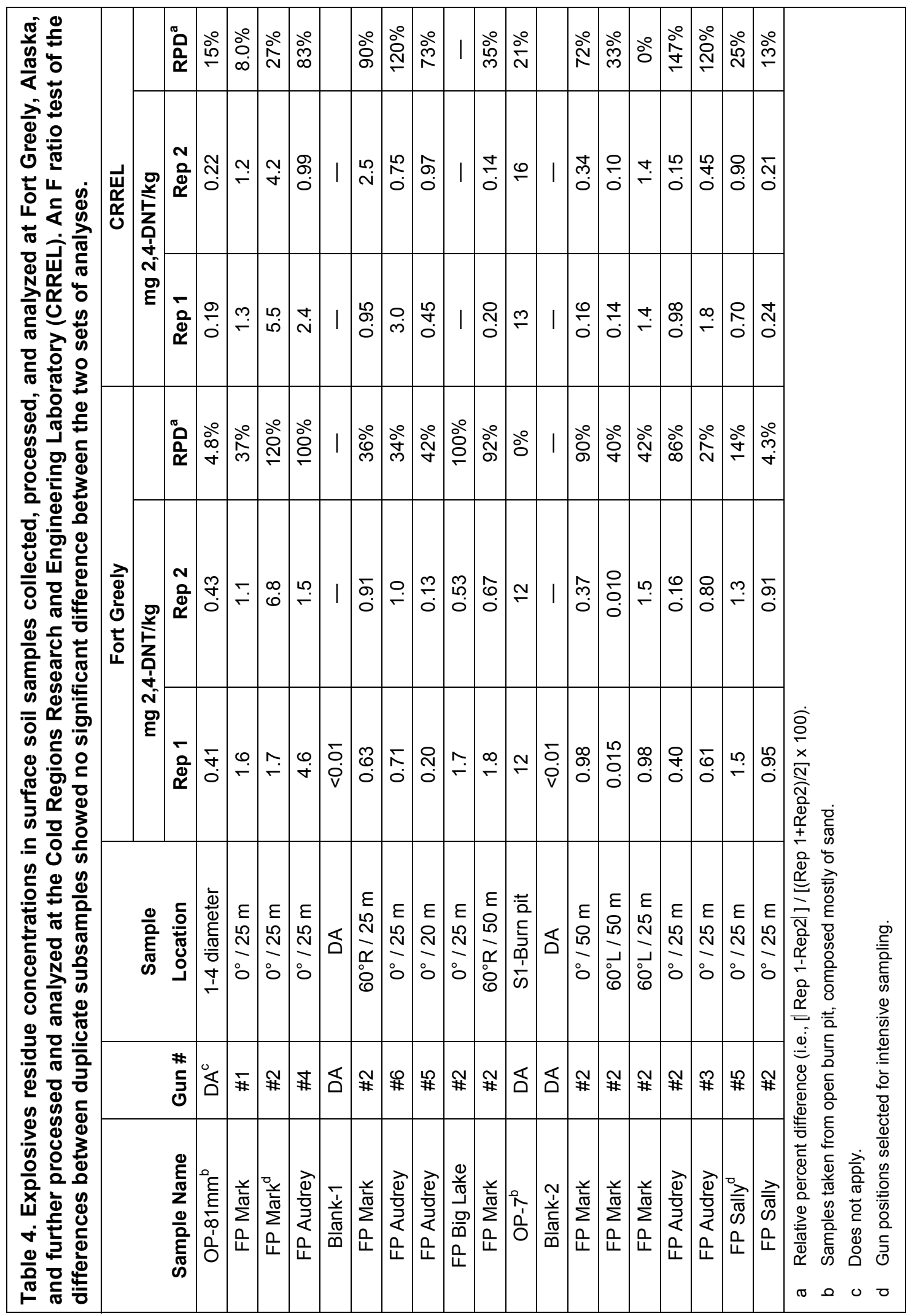


Off-site processing of these composite samples consisted of air drying, passing the sparsely vegetated samples through a \#10 sieve, grinding the sample with a ring mill for 60 seconds, and mixing the ground sample. For vegetated samples, woody vegetation and pebbles were removed, then the sample was ground for 90 seconds using a ring mill. To obtain a subsample for analysis, a 10$\mathrm{g}$ multi-increment sample was built for extraction with $20 \mathrm{~mL}$ of acetonitrile in a water-cooled sonic bath for 18 hours (U.S. EPA 1994). This procedure was based on experience gained with soils with explosives residues from a mortar impact range, a hand grenade range, and an anti-tank range (Walsh et al. 2002). However, for soils contaminated with propellant residues, the improvement in precision of concentration estimates has not been as great as that observed for explosives in unvegetated soils.

There are many types of laboratory sampling errors that can influence data quality: two of the more important ones are fundamental and segregation (Ramsey and Suggs 2001). Fundamental error deals with compositional heterogeneity and often can be managed for environmental soil samples by taking the appropriate size subsample. Segregation error is associated with distributional heterogeneity, which often can be addressed by providing equal access to the entire sample while subsampling and by collecting several increments. The sample grinding and subsampling protocol used in this study addressed both of these sources of laboratory sampling error. Grinding the sample reduced the particle size $(<2 \mathrm{~mm})$ to where a 10 -g subsample should have had less than 15\% relative standard deviation (Ramsey and Suggs 2001), for analytes that do not exist as "nuggets," and the subsampling procedure acquired a cross section of the entire layered pile (essentially creating a large number of increments). This level of laboratory subsampling precision was obtained for every analyte except tetryl when seven replicate subsamples were taken for analysis (Tables 2 and 3). Also, this level of precision was obtained for three of the four duplicate subsamples when the sample matrix was composed mostly of sand (Tables 3 and 4). However, when the sample matrix contained vegetation, the mean relative percent differences for the duplicate subsamples from Camp Ethan Allen and Fort Greely were, respectively, 48\% and 52\%. Possible explanations for this degree of imprecision between duplicates are a) the analytes of concern were present as discrete nuggets or existed in a shape that inhibits obtaining a uniform distribution, or b) the presence of vegetation in the matrix inhibited analyte homogenization.

The explosives residues deposited for the blowing in place of a $155-\mathrm{mm}$ howitzer round were crystalline pieces of TNT, which are easily broken into finer particles. The fibers of NC impregnated with 2,4-DNT, however, may not as easily be ground into a finer particle size and have a very different shape as 
compared to soil. Both of these samples contained vegetation that has a density and shape that is very different from soil.

Even though the vegetation was broken into smaller fibers during sample preparation, these differences in properties were essentially unchanged. The presence of vegetation also increased the period of time necessary to dry the sample prior to initiating sample preparation techniques (sieving and grinding). To avoid the delay caused by the necessity to dry a sample containing a lot of vegetation, and to address the potential influence of nuggets or distributional heterogeneity, the entire composite sample could be treated with acetone. Radtke et al. (2002) used this approach to extract explosives from both large composite and discrete samples. Another version of this approach is to create an acetonesample slurry, thereby attempting to dissolve and evenly distribute the explosives residues throughout the sample matrix prior to mixing thoroughly and subsampling.

\footnotetext{
* Personal communication, Sonia Thiboutot, Canadian National Defence Scientist,
} Defence Research Establishment-Valcartier (DREV), Val-Belair, Quebec, 2002. 


\section{SUMMARY}

The processing and subsampling protocol described here was successful in ranking explosives residue concentrations; however, additional improvements are needed. In general, crystalline explosives residues were easier to grind and to representatively subsample when present in sandy matrix. However, this was not the norm when in a vegetative matrix or when the analyte of concern was impregnated into another, less crystalline, material. The size distribution, shape, and composition of explosives residues resulting from projectile firing and detonation of munitions in addition to the vegetative state of the ground surface all most likely play a role in confounding the ability to obtain a representative subsample from large samples. Samples containing a lot of vegetation require a drying period that can be prohibitive for rapid on-site sample mechanical processing. Moreover, increasing the number of replicate subsamples analyzed can decrease the degree of uncertainty. However, doing so diminishes the efficiency of on-site analysis. To address all of these potential shortfalls, a promising approach would be to extract the entire composite or discrete sample with acetone for both on-site and subsequent off-site analysis. The disadvantage of using this approach is that large quantities of solvent are necessary. 


\section{REFERENCES}

ASTM (1998) Standard Guide for Laboratory Subsampling of Media Related to Waste Management Activities. ASTM D6323-98, Book of Standards Volume 11.04. American Society for Testing and Materials, West Conshohocken, Pennsylvania.

Grant, C.L., T.F. Jenkins, and A.R. Mudambi (1996) Comparison criteria for environmental chemical analyses for split samples sent to different laboratories: Corps of Engineers Archived Data. U.S. Army Cold Regions Research and Engineering Laboratory, Hanover, New Hampshire, Special Report 96-9.

Hewitt, A.D. (2002) Analysis of nitroglycerine in soils and on mortar fins using GC-TID. U.S. Army Engineer Research and Development Center, Cold Regions Research and Engineering Laboratory, Hanover, New Hampshire, Technical Report ERDC/CRREL TR-02-3.

Hewitt, A.D., T.F. Jenkins, and T.A. Ranney (2001) Field gas chromatography/ thermionic detector system for the analysis of explosives in soils. U.S. Army Engineer Research and Development Center, Cold Regions Research and Engineering Laboratory, Hanover, New Hampshire, Technical Report ERDC/CRREL TR-01-9.

Hewitt, A.D., T.F. Jenkins, T.A. Ranney, J.A. Stark, M.E. Walsh, S. Taylor, M.R. Walsh, D.J. Lambert, N.M. Perron, and N.H. Collins (in prep)

Estimates for explosives residue deposition from the detonation of Army munitions. U.S. Army Engineer Research and Development Center, Cold Regions Research and Engineering Laboratory, Hanover, New Hampshire.

Jenkins, T.F., and M.E. Walsh (1993) Instability of tetryl to soxhlet extraction. Journal of Chromatography A, 662: 178-184.

Jenkins, T.F., C.L. Grant, G.S. Brar, P.G. Thorne, P.W. Schumacher, and T.A. Ranney (1996) Assessment of sampling error associated with the collection and analysis of soil samples at explosives-contaminated sites. U.S. Army Cold Regions Research and Engineering Laboratory, Hanover, New Hampshire, Special Report 96-15.

Jenkins, T.F., C.L. Grant, G.S. Brar, P.G. Thorne, P.W. Schumacher, and T.A. Ranney (1997a) Assessment of sampling error associated with the collection and analysis of soil samples at explosives-contaminated sites. Field Analytical Chemistry and Technology, 1: 151-163. 
Jenkins, T.F., M.E. Walsh, P.G. Thorne, S. Thiboutot, G. Ampleman, T.A. Ranney, and C.L. Grant (1997b) Assessment of sampling error associated with collection and analysis of soil samples at a firing range contaminated with HMX. U.S. Army Cold Regions Research and Engineering Laboratory, Hanover, New Hampshire, Special Report 97-22.

Jenkins, T.F., T.A. Ranney, P.H. Miyares, N.H. Collins, and A.D. Hewitt (2000a)

Use of surface snow sampling to estimate the quantity of explosives residues resulting from land mine detonations. U.S. Army Engineer Research and Development Center, Cold Regions Research and Engineering Laboratory, Hanover, New Hampshire, Technical Report ERDC/CRREL TR-00-12.

Jenkins, T.F., T.A. Ranney, M.E. Walsh, P.H. Miyares, A.D. Hewitt, and N.H. Collins (2000b) Evaluating the use of snow-covered ranges to estimate explosives residues that result from detonation of Army munitions. U.S. Army Engineer Research and Development Center, Cold Regions Research and Engineering Laboratory, Hanover, New Hampshire, Technical Report ERDC/CRREL TR-00-15.

Jenkins, T.F., J.C. Pennington, T.A. Ranney, T.E. Berry Jr., P.H. Miyares, M.E. Walsh, A.D. Hewitt, N.M. Perron, L.V. Parker, C.A. Hayes, and E.G. Wahlgren (2001) Characterization of explosives contamination at military firing ranges. U.S.

Army Engineer Research and Development Center, Cold Regions Research and Engineering Laboratory, Hanover, New Hampshire, Technical Report ERDC TR-01-5 (http://www.crrel.usace.army.mil/techpub/CRREL_Reports/ reports/ERDC-TR-01-5.pdf).

Radtke C.W., D. Gianotto, and F.F. Roberto (2002) Effects of particulate explosives on estimating contamination at a historical explosives testing area. Chemosphere, 46: 3-9.

Ramsey, C.A., and J. Suggs (2001) Improving laboratory performance through scientific subsampling techniques. Environmental Testing and Analysis, March/April, 13-16.

Taylor, S., A.D. Hewitt, C. Hayes, L. Perovich, J. Lever, P.G. Thorne, and C. Daghlian (in prep) TNT particles for detonated $155-\mathrm{mm}$ howitzer rounds. To be submitted to Chemosphere. 
Thiboutot, S., G, Ampleman, and A.D. Hewitt (2002) Guide for characterization of sites contaminated with energetic materials. U.S. Army Engineer Research and Development Center, Cold Regions Research and Engineering Laboratory, Hanover, New Hampshire, Technical Report ERDC/CRREL TR-02-1.

U.S. Army Materiel Command (1972) Engineering Design Handbook: Principles of Explosive Behavior. AMC Pamphlet No. 706-180, Washington, D.C.

U.S. EPA (1994) Method 8330: Nitroaromatics and nitramines by HPLC. In Test Methods for Evaluating Solid Waste, Physical/Chemical Methods, Office of Solid Waste and Emergency Response. U.S. Environmental Protection Agency, Washington, D.C., SW-846, through update 4b (www.epa.gov/sw-846).

U.S. EPA (1999) Method 8095: Nitroaromatics and nitramines by GC-ECD. In Test Methods for Evaluating Solid Waste, Physical/Chemical Methods, Office of Solid Waste and Emergency Response. U.S. Environmental Protection Agency, Washington D.C., SW-846, through Update 4b (www.epa.gov/sw-846).

Walsh, M.E., C.A. Ramsey, and T.F. Jenkins (2002) The effect of particle size reduction by grinding on subsampling variance for explosives residues in soil. Chemosphere, 49: 1267-1273.

Walsh, M.E., C.M. Collins, A.D. Hewitt, M.R. Walsh, T.F. Jenkins, J.A. Stark, A.B. Gelvin, T. Douglas, N.M. Perron, D.J. Lambert, R.N. Bailey, and K. Myers (in prep) Range characterization studies at Donnelly Training Area, Alaska, 2001 and 2002. U.S. Army Engineer Research and Development Center, Cold Regions Research and Engineering Laboratory, Hanover, New Hampshire. 